\title{
OXIDAÇÃO DOS LIPÍDIOS EM CAFÉ ARÁBICA (Coffea arabica L.) E CAFÉ ROBUSTA (Coffea canephora P.)
}

\author{
LEDA BATTESTIN QUAST* \\ ARISLETE DANTAS DE AQUINO**
}

\begin{abstract}
O objetivo deste trabalho foi verificar a influência da matéria-prima e da temperatura de armazenamento na oxidação dos lipídios de café torrado e moído ao longo do tempo. Foram utilizados cafés arábica e robusta torrados, moídos e envasados em embalagens compostas de polietileno tereftalato/alumínio/polietileno de baixa densidade (PET/ALUM/PEBD). As amostras foram armazenadas em temperatura ambiente e em estufa a $38^{\circ} \mathrm{C}$ por 180 dias, sendo retiradas a cada 20 dias amostras de café para extração de óleo. A extração do óleo de café foi realizada em temperatura ambiente, utilizando-se solvente orgânico como meio extrator. Para a verificação da oxidação lipídica do óleo realizaram-se análises de índice de acidez e de dienos conjugados, cujos valores variaram de 2,3 a $4,4 \%$ e de 18 a $31,4 \%$ respectivamente. As análises do índice de acidez e dienos conjugados apresentaram acréscimo significativo nos primeiros 40 e 80 dias de armazenamento. Verificou-se que a temperatura de armazenamento não influenciou a oxidação lipídica, tendo o café robusta apresentado valores de dienos conjugados maiores que o café arábica.
\end{abstract}

PALAVRAS-CHAVE: CAFÉ; LIPÍDIOS; ÍNDICE DE ACIDEZ.

\section{INTRODUÇÃo}

De acordo com LINDLEY (1998), após a degradação microbiológica, a oxidação de compostos que provoca rancidez constitui a segunda maior causa de deterioração dos alimentos. A rancidez é percebida mediante compostos indesejáveis causados pelas reações de

* Pós-Graduada em Tecnologia de Alimentos, Universidade Federal do Paraná (UFPR), Curitiba, PR (e-mail: Ibattestin@uol.com.br).

** Professora Dra. em Engenharia Química, Departamento de Engenharia Química, UFPR, Curitiba, PR. 
oxidação e hidrólise de certos componentes que tornam o produto inaceitável para o consumo (TAWFIK e HUYGHEBAERT, 1997).

A rancidez oxidativa, um dos fatores críticos que afetam a qualidade do produto processado, ocorre em lipídios que contém ácidos graxos insaturados. Esses podem sofrer oxidação, degradação e polimerização via radicais livres, causando a formação de aldeídos, cetonas, ácidos, alcoóis e hidrocarbonetos, responsáveis pelas características organolépticas e físico-químicas associadas com a rancificação (HASENHUETTL e WAN, 1992).

O mecanismo de auto-oxidação dos lipídios pode ser descrito em várias etapas. Os radicais livres $(R)$ são formados de moléculas de lipídios $(\mathrm{RH})$ pela reação com o oxigênio em presença de catalisador como, por exemplo, a luz e o calor. Na etapa de propagação, os radicais livres reagem com o oxigênio para formar os radicais peróxi lípides (ROO), os quais reagem posteriormente com moléculas de lipídios formando os hidroperóxidos $(\mathrm{ROOH})$. Os peróxi lípides são chamados de produtos de primeira oxidação e podem ser usados como indicadores da qualidade e estabilidade dos óleos. Os peróxidos são instáveis e se decompõem, resultando no acúmulo de produtos de oxidação secundária como aldeídos, cetonas e dienos conjugados (THOMAIDIS e GEORGIOU, 1999). Na etapa de terminação ocorre a reação em cadeia entre os próprios radicais $(R)$, produzindo dímeros e polímeros. O processo de combinação de dois radicais requer baixa energia de ativação. Tal ocorrência é limitada pela concentração de radicais quando esses são requeridos para interagir num centro ativo específico das moléculas (WHEATLEY, 2000).

As etapas do mecanismo de auto-oxidação foram simplificadas por ZAMBIAZI (1999) da seguinte forma:

$\begin{array}{ll}\text { iniciação: } & \mathrm{RH}--->\mathrm{R}+\mathrm{H} \\ \text { propagação: } & \mathrm{R}+\mathrm{O}_{2}--->\mathrm{ROO} \\ & \mathrm{ROO}+\mathrm{RH}--->\mathrm{ROOH}+\mathrm{R} \\ \text { terminação: } & \mathrm{R}+\mathrm{R}--->\mathrm{RR} \\ & \mathrm{R}+\mathrm{ROO}--->\mathrm{ROOR} \\ & \mathrm{ROO}+\mathrm{ROO}--->\mathrm{ROOR}+\mathrm{O}_{2}\end{array}$


O café é rico em óleos, sendo que a variedade arábica contém de 12 a 18\% e a variedade robusta de 9 a 14\%. A maior parte desses óleos é constituída por ácido palmítico (34,5\%) e linoléico (40,3\%). O perfil de ácidos graxos dos lipídios do café é similar ao dos óleos vegetais comestíveis (TURATTI, 2001; VIDAL, 2001).

A oxidação dos lipídios em café causa importantes modificações em seu sabor e odor, que provocam perda de qualidade do produto. Durante o armazenamento do café torrado ocorre a liberação de diversos compostos, bem como o aparecimento de sabores indesejáveis devido à oxidação dos lipídios (PÁDUA et al., 2002). A oxidação do café inicia-se nos grãos crus e reflete-se nas características do produto final, devendo-se considerar o tempo de exposição do produto após a abertura da embalagem para uso doméstico (NICOLI et al., 1993).

A Figura 1 mostra a peroxidação do ácido linoléico que leva a formação de produtos de oxidação secundária, como os dienos conjugados.

Várias técnicas analíticas podem ser usadas para determinar a qualidade dos óleos. Os métodos mais tradicionais, como acidez do óleo e absorção no ultravioleta, são utilizados para medir a oxidação dos lipídios (THOMAIDIS e GEORGIOU, 1999).

Define-se índice de acidez em óleos como o número de miligramas de hidróxido de sódio necessários para neutralizar os ácidos livres de $1 \mathrm{~g}$ de amostra. $\mathrm{O}$ índice de acidez constitui medida quantitativa do conteúdo de ácidos graxos livres presentes no óleo. Seu valor depende da variedade do café, da região, do solo em que foi cultivado e das condições climáticas entre outros fatores. Esse índice também indica o estado de conservação dos lipídios (INSTITUTO ADOLFO LUTZ, 1985; PINTO et al., 2000).

A medida quantitativa dos dienos conjugados tem sido largamente utilizada para a determinação da oxidação de óleos e gorduras. A peroxidação dos ácidos graxos insaturados acompanha a mudança da dupla ligação na formação dos hidroperóxidos conjugados. Essa estrutura conjugada absorve fortemente a luz ultravioleta no comprimento de onda entre 232 e $234 \mathrm{~nm}$. A metodologia para determinação dos dienos conjugados é rápida e simples, pois requer quantidade pequena de amostra. Entretanto, o valor dos dienos 
conjugados depende da composição dos ácidos graxos da amostra não podendo ser usado diretamente na comparação do estado de oxidação de outras espécies de óleos (KULAS e ACKMAN, 2001). Os dienos conjugados podem eventualmente ter seu valor reduzido devido à interferência de bimoléculas que podem ser absorvidas na mesma região do espectro avaliado (WHEATLEY, 2000).

\section{FIGURA 1 - MECANISMO DE REAÇÃO - PEROXIDAÇÃO DO} ÁCIDO LINOLÉICO
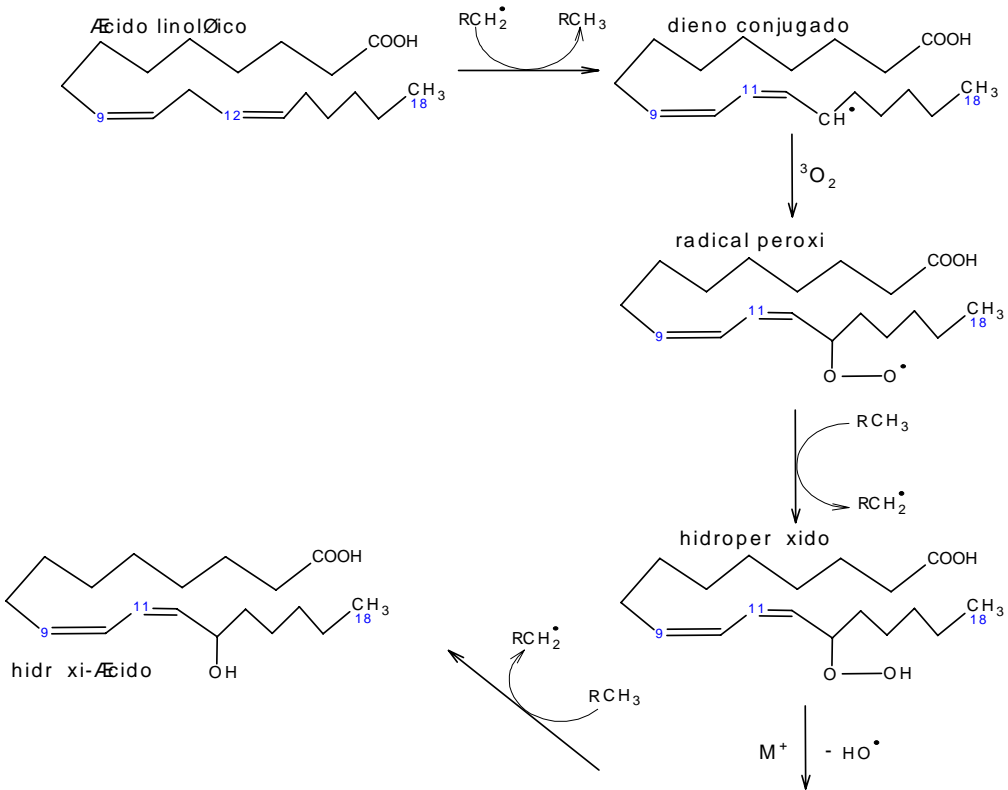

$$
\downarrow{ }^{3} \mathrm{O}_{2}
$$
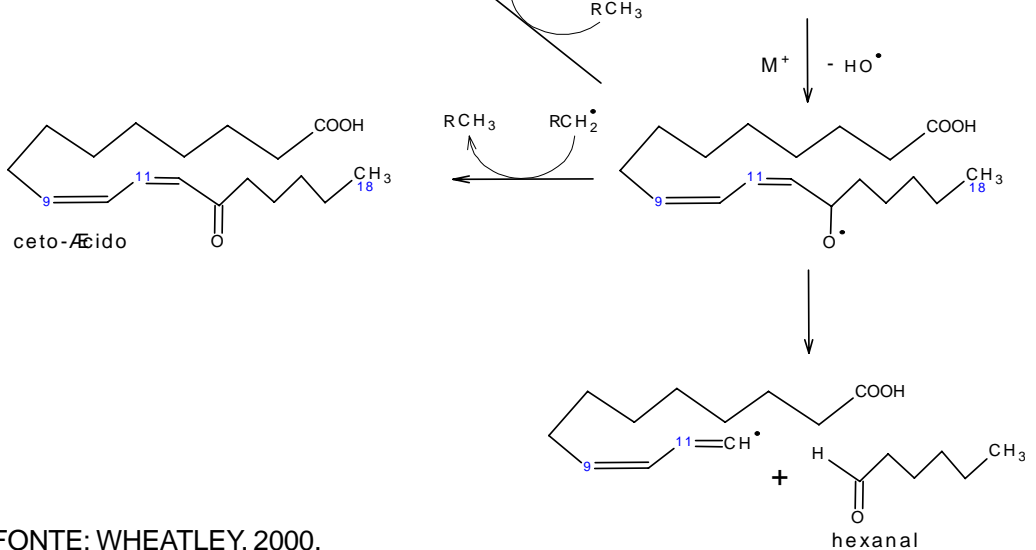

FONTE: WHEATLEY, 2000.

hexanal 
O objetivo deste trabalho foi verificar a influência da matéria-prima e da temperatura de armazenamento na oxidação dos lipídios de café torrado e moído ao longo do tempo.

\section{MATERIAL E MÉTODOS}

Para este estudo foram utilizados cafés da espécie arábica e robusta, provenientes de uma indústria de café do estado do Paraná. Realizouse o processo de torrefação até o ponto em que a coloração dos grãos foi denominada média, com valor numérico correspondente de 45IR, medida pelo índice de reflectância da luz. Os cafés torrados foram moídos e envasados em embalagens compostas de polietileno tereftalato/alumínio/polietileno de baixa densidade (PET/ALUM/PEBD), tipo almofada com $250 \mathrm{~g}$ cada. As amostras de café foram estocadas em temperatura ambiente e em estufa a $38^{\circ} \mathrm{C}$ durante 180 dias. Considerou-se a temperatura ambiente de $25^{\circ} \mathrm{C}$, pois durante o período avaliado a temperatura média mínima foi de $10^{\circ} \mathrm{C}$ e a média máxima de $30^{\circ} \mathrm{C}$. A cada 20 dias, amostras de café arábica e robusta estocadas em temperatura ambiente e em estufa foram retiradas para análise.

\subsection{CARACTERIZAÇÃO QUÍMICA DA MATÉRIA-PRIMA}

A caracterização química das matérias-primas consistiu nas análises de umidade, cinzas, lipídios e proteínas (proteína bruta), efetuadas anteriormente ao início dos experimentos. As medidas do teor de umidade das amostras foram realizadas utilizando-se sistema de secagem por infravermelho (IR), Mettler LP 16, acoplado em balança semi-analítica marca Micronal $B$ 360. Para isso, $3 \mathrm{~g}$ de amostra foram submetidas a $130^{\circ} \mathrm{C}$ durante o período de 10 minutos.

Determinou-se o teor de cinzas de acordo com metodologia da AOAC (1990), sendo cerca de $5 \mathrm{~g}$ de café torrado e moído carbonizadas em bico de Bunzen e incineradas em mufla a $550^{\circ} \mathrm{C}$ até obter-se resíduo de coloração cinza esbranquiçada. As cinzas de café foram resfriadas até temperatura ambiente em dessecador.

O teor de lipídios foi determinado segundo a AOAC (1990), mediante extração em equipamento Soxlet, utilizando cerca de $2 \mathrm{~g}$ de café 
torrado e moído. A extração do óleo foi efetuada com éter etílico por cerca de $16 \mathrm{~h}$.

Determinou-se o valor de proteínas (proteína bruta) de acordo com o descrito por ANGELLUCI (1982) e pela AOAC (1990). Transferiu-se cerca de $0,5 \mathrm{~g}$ de café torrado e moído para balão de Kjedhal ao qual foram adicionadas $18 \mathrm{~g}$ de sulfato de potássio anidro, $1 \mathrm{~g}$ de sulfato de cobre e $25 \mathrm{~mL}$ de ácido sulfúrico concentrado. A solução foi digerida, destilada e titulada utilizando-se hidróxido de sódio $0,1 \mathrm{~N}$. Calculouse a proteína bruta mediante valores de cafeína para as espécies arábica e robusta retirados da literatura (MATIELLO, 1991). O cálculo da proteína bruta é dado por:

Prote na Bruta $(\%)=(\%$ Prote na total $-(\%$ cafe na $\times 0,1486)) \times 6,25$

\subsection{EXTRAÇÃO DO ÓLEO DE CAFÉ PARA ANÁLISE DO ÍNDICE DE ACIDEZ E DOS DIENOS CONJUGADOS}

O processo de extração do óleo do café foi conduzido em laboratório, utilizando-se solvente orgânico como meio extrator. Para a extração do óleo foram usadas $100 \mathrm{~g}$ de café, distribuídas em 5 frascos erlenmeyer adicionados com $100 \mathrm{~mL}$ de clorofórmio de pureza analítica (marca Synth). A solução de café com o clorofórmio (20 g de café para $100 \mathrm{~mL}$ de clorofórmio) permaneceu sob agitação constante em temperatura ambiente por 2 horas. De acordo com a literatura, o processo de extração do óleo deve ser conduzido em temperatura ambiente para evitar a oxidação dos lipídios (NICOLI et al., 1993).

A fase líquida, contendo solvente e óleo, foi separada da fase sólida (café torrado) por filtração em filtro Whatman número 1. Efetuou-se a separação do óleo sob vácuo em rotavapor marca Quimis, mantendose a temperatura de $38 \pm 1^{\circ} \mathrm{C}$. Evaporou-se o resíduo de solvente remanescente no óleo de café em atmosfera de nitrogênio conforme descrito por VIDAL (2001). O óleo de café extraído foi acondicionado em frascos de vidro âmbar e armazenado em freezer a -18ํㅡ até a realização das análises.

Os valores do índice de acidez do óleo foram determinados conforme descrito por VIDAL (2001) e pelas normas do INSTITUTO ADOLFO 
LUTZ (1985) com redução da quantidade de óleo utilizada (invés de $2 \mathrm{~g}$ utilizou-se cerca de $0,5 \mathrm{~g}$ de óleo). O óleo foi dissolvido com 10 $\mathrm{mL}$ de álcool etílico neutralizado anteriormente por titulação com $\mathrm{NaOH}$ $0,01 \mathrm{~N}$, usando-se fenoftaleína como indicador. Efetuou-se a titulação do óleo com $\mathrm{NaOH} 0,01 \mathrm{~N}$ até a coloração rosa persistir por 30 segundos. Determinou-se a acidez do óleo sob a forma de ácido oléico como:

"ndice de acidez $(\%)=\frac{\mathrm{mL} \mathrm{NaOH} 0,01 \mathrm{~N} \times 0,282}{\text { massa da amostra }}$

A análise dos dienos conjugados foi realizada de acordo com o método II.D.22 descrito pela IUPAC (1979), utilizando-se Espectofotômetro Ultravioleta Visível (UV-VIS) marca Espectrônic (Modelo Gênesis-2) e as medidas da absorbância efetuadas no comprimento de onda de $232 \mathrm{~nm}$. Para tal, colocou-se cerca de 0,2 g de óleo em balão volumétrico de $25 \mathrm{~mL}$ e completou-se o volume do balão com isoctano (marca Synth). Para a leitura utilizou-se célula de quartzo de $1 \mathrm{~cm}$ e isoctano como branco. A medida dos dienos conjugados foi determinada pela fórmula abaixo, sendo que a concentração da amostra é a quantidade de óleo dissolvida para $100 \mathrm{~mL}$ de isoctano:

Dienos conjugados $(\%)=\frac{\text { absorb nci a }}{\text { Concentra }{ }^{\mathrm{a}} \mathrm{O} \text { da amostra } \mathrm{x} \text { larg ura da cubeta }}$

\section{RESULTADOS E DISCUSSÃO}

A caracterização química das amostras de café utilizadas neste estudo são apresentadas na Tabela 1.

Em relação ao teor de umidade, os cafés arábica e robusta apresentaram valores de umidade muito semelhantes. A diferença no teor de umidade entre os dois cafés, embora muito pequena, pode estar relacionada com a umidade inicial dos grãos e também com as condições do processo de torrefação.

Os resultados obtidos para o teor de cinzas e proteínas nos cafés arábica e robusta enquadraram-se nas faixas apresentadas na literatura por ENCARNAÇÃO e LIMA (2003) e MATIELLO (1991). Em 
relação ao conteúdo de lipídios, o café arábica apresentou teor maior que o café robusta. Esse comportamento está de acordo com os resultados obtidos por MAZZAFERA et al. (1998).

TABELA 1 - CARACTERIZAÇÃO QUÍMICA DA MATÉRIA-PRIMA

\begin{tabular}{lcc}
\hline Caracter sticas & \multicolumn{2}{c}{$\%$ MatØia Seca } \\
\cline { 2 - 3 } & CafØArAßica & CafØRobusta \\
\hline Umidade & 2,03 & 2,10 \\
Cinzas & 4,33 & 4,64 \\
Lip dios & 14,14 & 9,28 \\
Prote nas (Prote na Bruta) & 12,67 & 12,43 \\
\hline
\end{tabular}

A Figura 2 apresenta os resultados obtidos para o índice de acidez em óleo extraído dos cafés arábica e robusta que foram armazenados em temperatura ambiente e em estufa por 180 dias.

\section{FIGURA 2 - ÍNDICE DE ACIDEZ EM ÓLEO DE CAFÉ ARÁBICA E ROBUSTA}

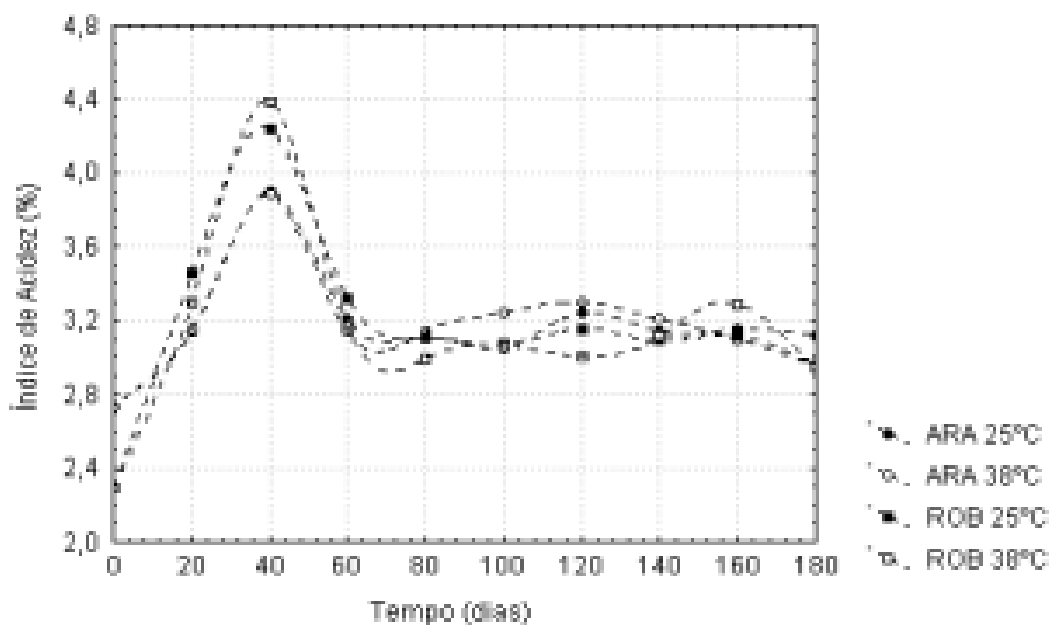

ARA $25^{\circ} \mathrm{C}=$ Café arábica armazenado em temperatura ambiente; ARA $38^{\circ} \mathrm{C}=$ Café arábica armazenado em estufa; $\mathrm{ROB} 25^{\circ} \mathrm{C}=$ Café robusta armazenado em temperatura ambiente; $\mathrm{ROB} 38^{\circ} \mathrm{C}=$ Café robusta armazenado em estufa. 
Todas as amostras apresentaram aumento no índice de acidez do óleo durante os primeiros 40 dias de armazenamento (Figura 2). Tal comportamento foi verificado por VIDAL (2001) durante o mesmo período e por TAWFIK e HUYGHEBAERT (1999) utilizando óleo de palma e óleo de girassol. De acordo com TAWFIK e HUYGHEBAERT (1999), a presença do oxigênio no interior das embalagens pode ser responsável pela oxidação dos lipídios, causando aumento no índice de acidez. Segundo tais autores, a evolução da oxidação lipídica depende da susceptibilidade oxidativa de cada tipo de óleo.

Após o período inicial de 40 dias ocorreu decréscimo no índice de acidez, cujos valores permaneceram constantes a partir dos 60 dias de armazenamento. TURATTI (2001) realizou estudo de acidez com óleo extraído do café armazenado por 150 dias. Observou que durante o período avaliado não houve alterações nos valores da acidez do óleo e sugeriu que esse comportamento está relacionado com a ação da enzima lipase. A enzima lipase atua enquanto o óleo está dentro do grão, mas após a extração esse contato cessa e conseqüentemente a acidez estabiliza.

Os valores do índice de acidez mostraram-se muito semelhantes para os cafés arábica e robusta armazenados em temperatura ambiente e em estufa (Figura 2). O calor induz a oxidação lipídica, entretanto, a maioria dos estudos de oxidação lipídica referem-se aos lipídios na sua forma pura. Nos alimentos que contém lipídios (caso do café), além do efeito da temperatura, as reações de degradação são afetadas por diversas interações entre os compostos existentes. Com isso, é possível que ocorra mudança na estabilidade do óleo de café durante o armazenamento do produto.

A Figura 3 apresenta os resultados obtidos para os dienos conjugados em óleo extraído dos cafés arábica e robusta, armazenados em temperatura ambiente e em estufa por 180 dias.

As amostras avaliadas apresentaram acréscimo nos valores dos dienos conjugados até cerca de 80 dias de armazenamento (Figura 3 ), seguidos por tendência de estabilização. $O$ aumento nos valores dos dienos conjugados também pode estar relacionado com reações de oxidação dos lipídios, que ocorrem na presença do oxigênio. 0 café utilizado neste estudo foi acondicionado em embalagens sujeitas a troca de gases, o que favorece as reações de oxidação do produto. 


\section{FIGURA 3 - DIENOS CONJUGADOS EM ÓLEO DE CAFÉS ARÁBICA E ROBUSTA}

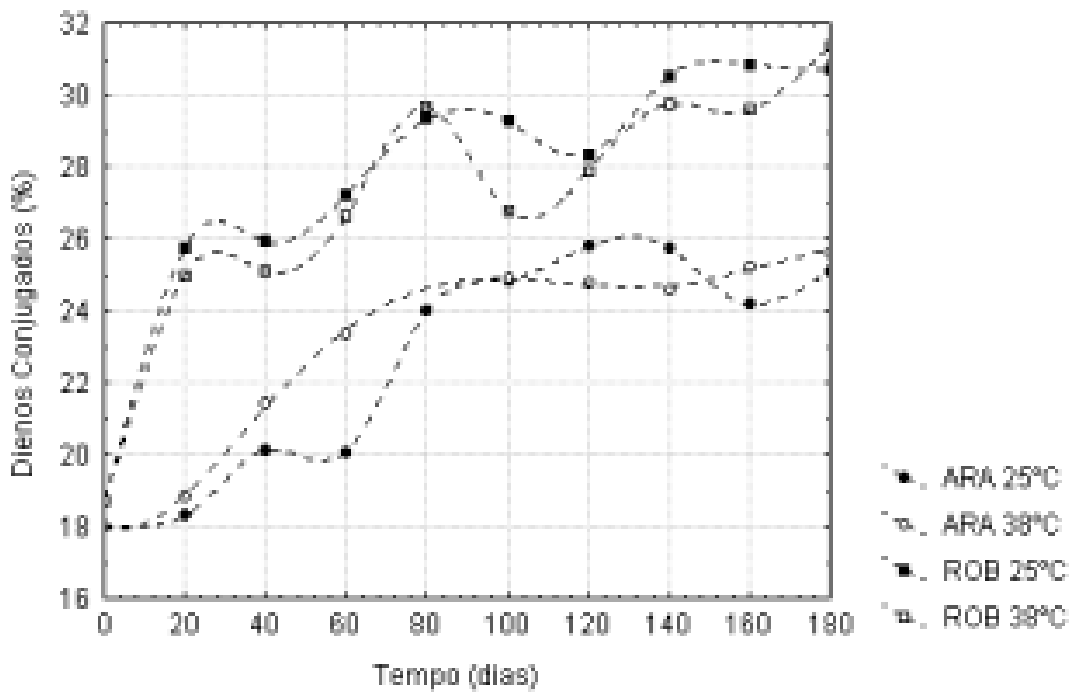

ARA $25^{\circ} \mathrm{C}=$ Café arábica armazenado em temperatura ambiente; ARA $38^{\circ} \mathrm{C}=$ Café arábica armazenado em estufa; ROB $25^{\circ} \mathrm{C}$ = Café robusta armazenado em temperatura ambiente; $\mathrm{ROB} 38^{\circ} \mathrm{C}=$ Café robusta armazenado em estufa.

Da mesma forma como ocorreu com o índice de acidez, os cafés armazenados em estufa revelaram valores de dienos conjugados muito semelhantes aos cafés armazenados em temperatura ambiente. Em contrapartida, o café robusta apresentou valores de dienos conjugados superiores ao café arábica.

A análise dos dienos conjugados não é freqüentemente utilizada em óleo de café e sim em óleos de soja, cujos valores dos dienos são menores que os obtidos em óleo de café. Considerando esse fato, a análise de dienos em óleo de café foi interessante como medida de comparação dos óleos de café das espécies arábica e robusta submetidos a diferentes tratamentos. 


\section{CONCLUSÃO}

Verificou-se acréscimo nos valores do índice de acidez e dos dienos conjugados nos primeiros 40 e 80 dias de armazenamento, respectivamente. Esse acréscimo pode estar relacionado com a oxidação dos lipídios na presença do oxigênio no interior da embalagem.

A temperatura de armazenamento não exerceu influência na oxidação dos lipídios, tanto para o café arábica como para o café robusta.

O tipo de café influenciou a oxidação dos lipídios, sendo que o café robusta apresentou maiores valores de dienos conjugados que o café arábica. No entanto, não foi possível detectar essa diferença pela análise do índice de acidez.

\section{ABSTRACT \\ LIPIDS OXIDATION IN ARABIC (Coffea arabica L.) AND ROBUST (Coffea canephora P.) COFFEE}

The aim of the present work was to verify the influence of the raw material and storage temperature in lipids oxidation of roasted and milled coffee through time. Arabic and robust coffee roasted, milled and packed in Terephthalate/Aluminum/ Polyethylene (PET/ALUM/PEBD) low density packs, was utilized. Samples were stored at room temperature and in stove at 38ㅇ $\mathrm{C}$ for 180 days, being withdrawn every 20 days for oil extraction. Coffee oil extraction was realized at room temperature by utilizing an organic solvent as extraction media. To verify the lipids oxidation of the oil, analysis of acidity index and conjugated diene were realized, which values varied from 2.3 to $4.4 \%$ and of 18 to $31.4 \%$ respectivelly. The analysis of acidity index and conjugated dienes presented significant enhance at 40 and 80 days of storage. It was verified that storage temperature didn't influence the lipids oxidation, and robust coffee presented higher values of conjugated dienes than robust coffee.

KEY-WORDS: COFFEE; LIPIDS; ACIDITY INDEX.

\section{REFERÊNCIAS}

1 ANGELUCCI, E. Análise química do café. Campinas: ITAL, 1982. 85 p. (Apostila).

2 AOAC. Association of Official Analytical Chemists. Official methods of the AOAC International. $15^{\text {th }}$ ed. Washington, $1990.110 \mathrm{p}$. 

2003. 64 p. (Embrapa Café, Documento 1).

HASENHUETTL, G.L.; WAN, P.J. Temperature effects on the determination of oxidative stability with the metrohm rancimat. Journal of American Oil Chemists' Society, v.69, n.6, p.525-527, Jun. 1992.

INSTITUTO ADOLFO LUTZ. Normas Analíticas do Instituto Adolfo Lutz. São Paulo, 1985. v. 1.

IUPAC. International Union of Pure and Applied Chemistry. Standard methods for the analysis of oil, fats and derivates. Oxford: Pergamon Press, 1979. $170 \mathrm{p}$.

KULAS, E.; ACKMAN, R. Different tocopherols and the relationship between two methods for determination of primary oxidation products in fish oil. Journal of Agricultural and Food Chemistry, v.49, p.1724-1729, 2001.

LINDLEY, M.G. The impact of food processing on antioxidants in vegetable oils, fruits and vegetables. Trends in Food Science e Technology, v.9, p.336-340, 1998.

MATIELO, J.B. O café: do cultivo ao consumo. São Paulo: Globo, 1991. 320 p.

MAZZAFERA, P.; SOAVE, D.; ZULO, M.A.T.; GUERREIRO FILHO, O. Oil content of green beans from some species. Bragantia, v.57, n.1, p. 45-48, 1998.

NICOLI, M.C.; INNOCENTE, N.; PITTIA, P.; LERICI, C.R. Staling of roasted coffee: volatile release and oxidation reactions during storage. In: ASSOCIATION SCIENTIFIC INTERNATIONAL OF COFFE, 15., Montpellier, 1993. Proceedings... Montpellier: ASIC, 1993. p. 557-566.

PÁDUA, F.R.M.; PEREIRA, R.G.F.A.; LOPES, L.M.V.; MELO, W.C.; MORAIS, A.R DE. Avaliação sensorial e da composição química, durante o armazenamento, do café torrado e moído. Revista Brasileira de Armazenamento, Especial Café, Viçosa, v.5, p.15-21, 2002.

PINTO, N.A.V.D.; VILAS BOAS, B.M.; FERNANDES, S.M.; CARVALHO, V.D. de. Composição química de diferentes padrões de bebida para preparo de café expresso provenientes da região sul de Minas Gerais. In: SIMPÓSIO DE PESQUISA DOS CAFÉS DO BRASIL, 2000, Poços de Caldas. Resumos expandidos... Brasília: EMBRAPA Café, 2000. p. 665-668.

14 TAWFIK, M.S.; HUYGHEBAERT,A. Interation of packaging materials and vegetable oils: oil stability. Food Chemistry, v. 64, p.451-459, 1997.

15 THOMAIDIS, N.S.; GEORGIOU, C.A. Edible oil analysis by flow injection. Laboratory Automation and Information Management, v.34, p.101-114, 1999.

16 TURATTI, J.M. Extração e caracterização de óleo de café. In: SIMPÓSIO DE PESQUISA DOS CAFÉS DO BRASIL, 2., 2001, Vitória. Resumos expandidos... Brasília: EMBRAPA Café, p. 1533-1539, 2001.

VIDAL, H.M. Composição lipídica e a qualidade do café (Coffea arábica L.) durante armazenamento. Viçosa, MG, 2001. 93 f. Dissertação (Mestrado em Agroquímica) Universidade Federal de Viçosa.

18 ZAMBIAZI, C. Oxidation reactions of vegetable oils and fats. Ciência e Tecnologia de Alimentos, Campinas, v.33, n.1, p.1-7, jan./jun., 1999.

WHEATLEY, R.A. Some trends in the analytical chemistry of lipid peroxidation. Trends in Analytical Chemistry, v.19, n.10, p.617-628, 2000. 